Aim of the study: Interleukin (IL)-35 is composed of two subunits: Epstein-Barr virus-induced gene 3 (EBI3) and IL-12p35. Recently, overexpression of IL-35 has been found in several types of cancers. However, its clinical significance in nasopharyngeal carcinoma is still obscure. We have studied the clinical significance of IL-35 expression and its correlation with outcome of nasopharyngeal carcinoma patients.

Material and methods: Interleukin 35 expression was investigated in 80 nasopharyngeal carcinoma cases by immunohistochemistry. Moreover, Fisher's exact test, Kaplan-Meier plots, and Cox proportional hazards regression were utilized to analyse these results.

Results: In the present study, IL-35 is highly expressed in the majority of nasopharyngeal carcinoma samples. $\mathrm{EBI} 3$ and p35 immunoreactivity in nasopharyngeal carcinoma samples was $67.5 \%$ and $51.3 \%$, respectively. Both $\mathrm{EBI} 3$ and $\mathrm{p} 35$ expressions were significantly associated with advancement of tumour stage. In addition, EBI3 expression was also correlated with lymph node metastasis. Further analysis showed that $\mathrm{EBI} 3$ or p35 staining indicated unfavourable prognosis $(p<0.05)$. Multivariate analysis suggested EBI3 was an independent prognostic predictor $(p<0.05)$.

Conclusions: Our results indicate for the first time that IL-35 is correlated with progression of nasopharyngeal carcinoma. Therefore, IL-35 may be a useful target for the treatment of nasopharyngeal carcinoma.

Key words: nasopharyngeal carcinoma, IL-35, prognosis, immunohistochemistry.

Contemp Oncol (Pozn) 2015; 19 (2): 120-124 DOI: $10.5114 /$ wo.2014.44754

\section{Interleukin 35 is an independent prognostic factor and a therapeutic target for nasopharyngeal carcinoma}

\author{
Yongquan Zhang ${ }^{1}$, Hong Sun ${ }^{2}$, Hui Wu ${ }^{3}$, Qindong Tan ${ }^{4}$, Kai Xiang ${ }^{4}$
}

1Department of Otolaryngology - Head and Neck Surgery, the third Xiangya Hospital, Central South University, Changsha, 410013, P.R. of China

${ }^{2}$ Department of Otolaryngology - Head and Neck Surgery, Xiangya Hospital,

Central South University, Changsha, 410008, P.R. of China

'Department of Otolaryngology, the Affiliated People's Hospital of Fujian University

of Traditional Chinese Medicine, Fuzhou, Fujian 350004, P.R. of China

${ }^{4}$ Department of Anaesthesiology, Xiangya Hospital of Central-South University,

Changsha, Hunan 410008, P.R. of China

\section{Introduction}

Nasopharyngeal carcinoma is one of the most common cancers in Southern China, and it is a disease with a distinct ethnic and geographic distribution [1, 2]. In contrast with other cancers, most nasopharyngeal carcinoma cases are undifferentiated, and the majority of newly diagnosed nasopharyngeal carcinoma patients have lymph node metastases. To date, it is known that Epstein-Barr virus (EBV) infection play a key role in pathogenesis of nasopharyngeal carcinoma. However, the molecular mechanisms involved in the progression and prognosis of nasopharyngeal carcinoma have not been fully elucidated.

Interleukin (IL)-35, a new immune-suppressing cytokine, is a heterodimeric cytokine composed of the p35 subunit of IL-12 and the EBI3 (Epstein-Barr virus-induced gene 3) subunit [3-6]. Interleukin 35 is expressed in non-stimulated murine regulatory $T$ cells $\left(T_{\text {reg }}\right)$ and it is considered to be a characteristic marker for $T_{\text {reg }}$ cells [7-10]. It is known that the anti-tumour activities of IL-12 have been extensively studied in a variety of human cancers [11]. Because IL-35 shares the IL-12p35 and EBI3 subunits with IL-12, it might participate in the development or progression of cancers. Recently, immunohistochemical analysis EBI3 has up-regulated in acute myeloid leukaemia cells [12] and Hodgkin lymphoma cells [13, 14]. Moreover, expressions of EBI3 and IL-12p35 are also enhanced in lung cancer [15] and colon cancer [16].

However, there has been no study concerning the correlation between IL-35 expression and clinicopathological parameters or prognosis in patients with nasopharyngeal carcinoma. In the present study, we determined the expression levels of the IL-35 in nasopharyngeal carcinoma cells, and investigated the possible role of IL-35 in the prognosis of nasopharyngeal carcinoma patients.

\section{Material and methods}

Patients and tissue samples

Paraffin-embedded specimens from 80 patients with nasopharyngeal carcinoma were collected from the Department of Pathology, Xiangya hospital, from 2003 to 2004. The median follow-up period for the survivors was 50.8 (range, 9-93) months. Tumour stage was classified according to the pathology tumour-node-metastasis (pTNM) system (AJCC/UICC 2002). Histology was classified based on the World Health Organization (WHO) classi- 
fication. The specimens were diagnosed pathologically by two pathologists. None of the patients had received radiotherapy or chemotherapy. Clinicopathological factors for these nasopharyngeal carcinoma patients are detailed in Table 1. Patients whose cause of death remained unknown were excluded from our study. Informed consent on the collection of samples was obtained from each patient. The Institutional Research Medical Ethics Committee of Xiangya Hospital granted approval for this study.

\section{Immunohistochemistry staining}

Paraffin-embedded sections were deparaffinised and rehydrated in graded concentrations of ethanol. The sections were submerged in citrate antigenic retrieval buffer and subjected to high pressure for antigenic retrieval. Then slides were incubated with EBI3 (1: 200 dilution, sc-32868, Santa Cruz Biotechnology) and p35 (1 : 150 dilution, sc-7925, Santa Cruz Biotechnology) at $4^{\circ} \mathrm{C}$ overnight. Labelling was detected by adding biotinylated secondary antibodies (Maxim-Bio, Fuzhou, China), avidin-biotin complex (Maxim-Bio), and stained with DAB (Maxim-Bio). Finally, sections were counterstained with haematoxylin and viewed under a light microscope. A negative control was obtained by replacing the primary antibody with a normal murine lgG, and human colorectal cancer tissue was used as positive control. Expressions of EBI3 and p35 were scored according to the positive percentage and staining intensity of the stained cancer cells. The percentage positivity was scored as 0 (0-25\%), 1 (26-50\%), 2 (51-75\%), and 3 (> 75\%). The staining intensity was scored as 0 (no staining), 1 (weakly stained), 2 (moderately stained), and 3 (strongly stained). If the product of multiplication between staining intensity and the percentage of positive cells was $\geq 2$, it was taken as immunoreaction positive (+).

\section{Statistical analysis}

All statistical analyses were carried out using SPSS13.0 software. Fisher's exact test was used to analyse the correlation between the clinicopathological characteristics and EBI3, p35 expression. Survival curves were obtained with the Kaplan-Meier method. Multivariate analysis was performed using Cox proportional hazards regression. $p<0.05$ denotes the presence of a statistically significant difference.

\section{Results}

\section{EBI3 and p35 expression in nasopharyngeal carcinoma cells}

To explore the expression levels of EBI3 and p35 in nasopharyngeal carcinoma cells, immunohistochemical assay was used in 80 cases. Expression levels of EBI3 and p35 were increased in these series of nasopharyngeal carcinoma samples, as shown in Figure 1. In our experimental group, EBI3 expression was found in 54 cases (67.5\%, 54/80). In addition, p35 immunoreactivity was present in 41 cases $(51.3 \%, 41 / 80)$. Compared with no staining in the normal nasopharyngeal mucosa, EBI3 and p35 were over-expressed in the cytoplasm of the nasopharyngeal carcinoma cells (Fig. 1).

\section{Correlation of EBI3 and p35 expression with clinicopathological factors of nasopharyngeal carcinoma patients}

To further investigate the clinical significance of IL-35 in nasopharyngeal carcinoma specimens, the correlation between IL-35 expression and clinicopathological factors was explored. As summarised in Table 1, EBI3 expression was significantly associated with tumour stage $(p=0.003)$ and lymph node metastasis $(p=0.018)$. There were no sig-

Table 1. Correlation of EBI3 and p35 expression with clinicopathological factors of nasopharyngeal carcinoma patients

\begin{tabular}{|c|c|c|c|c|c|c|c|}
\hline Variable & Cases & $\begin{array}{c}\text { EBI3 } \\
\text { expression } \\
\text { Negative }\end{array}$ & $\begin{array}{c}p 35 \\
\text { expression } \\
\text { Positive }\end{array}$ & $p$ & Negative & Positive & $p$ \\
\hline $\begin{array}{l}\text { Gender } \\
\text { male } \\
\text { female }\end{array}$ & $\begin{array}{l}41 \\
39\end{array}$ & $\begin{array}{c}11 \\
7\end{array}$ & $\begin{array}{l}30 \\
24\end{array}$ & 0.787 & $\begin{array}{l}18 \\
21\end{array}$ & $\begin{array}{l}23 \\
18\end{array}$ & 0.502 \\
\hline $\begin{array}{l}\text { Age (years) } \\
\quad \geq 48 \\
<48\end{array}$ & $\begin{array}{l}35 \\
45\end{array}$ & $\begin{array}{l}10 \\
15\end{array}$ & $\begin{array}{l}25 \\
30\end{array}$ & 0.808 & $\begin{array}{l}19 \\
20\end{array}$ & $\begin{array}{l}16 \\
25\end{array}$ & 0.499 \\
\hline $\begin{array}{l}\text { Histological subtype } \\
\text { DNKC } \\
\text { UDC }\end{array}$ & $\begin{array}{l}11 \\
69\end{array}$ & $\begin{array}{c}6 \\
20\end{array}$ & $\begin{array}{c}5 \\
49\end{array}$ & 0.162 & $\begin{array}{c}4 \\
35\end{array}$ & $\begin{array}{c}7 \\
34\end{array}$ & 0.520 \\
\hline $\begin{array}{l}\text { Tumour stage } \\
\qquad \begin{array}{l}\text { I + II } \\
\text { III + IV }\end{array}\end{array}$ & $\begin{array}{l}22 \\
58\end{array}$ & $\begin{array}{l}13 \\
13\end{array}$ & $\begin{array}{c}9 \\
45\end{array}$ & 0.003 & $\begin{array}{l}17 \\
22\end{array}$ & $\begin{array}{c}5 \\
36\end{array}$ & 0.002 \\
\hline $\begin{array}{l}\text { T classification } \\
\text { T1-T2 } \\
\text { T3-T4 }\end{array}$ & $\begin{array}{l}33 \\
47\end{array}$ & $\begin{array}{c}7 \\
19\end{array}$ & $\begin{array}{l}26 \\
28\end{array}$ & 0.092 & $\begin{array}{l}18 \\
21\end{array}$ & $\begin{array}{l}15 \\
26\end{array}$ & 0.496 \\
\hline $\begin{array}{l}\text { Lymph node metastasis } \\
\text { NO-N1 } \\
\text { N2-N3 }\end{array}$ & $\begin{array}{l}56 \\
24\end{array}$ & $\begin{array}{c}23 \\
3\end{array}$ & $\begin{array}{l}33 \\
21\end{array}$ & 0.018 & $\begin{array}{l}29 \\
10\end{array}$ & $\begin{array}{l}27 \\
14\end{array}$ & 0.465 \\
\hline
\end{tabular}

DNKC - differentiated non-keratinising carcinoma; UDC - undifferentiated carcinoma 
$\mathrm{EBI} 3$
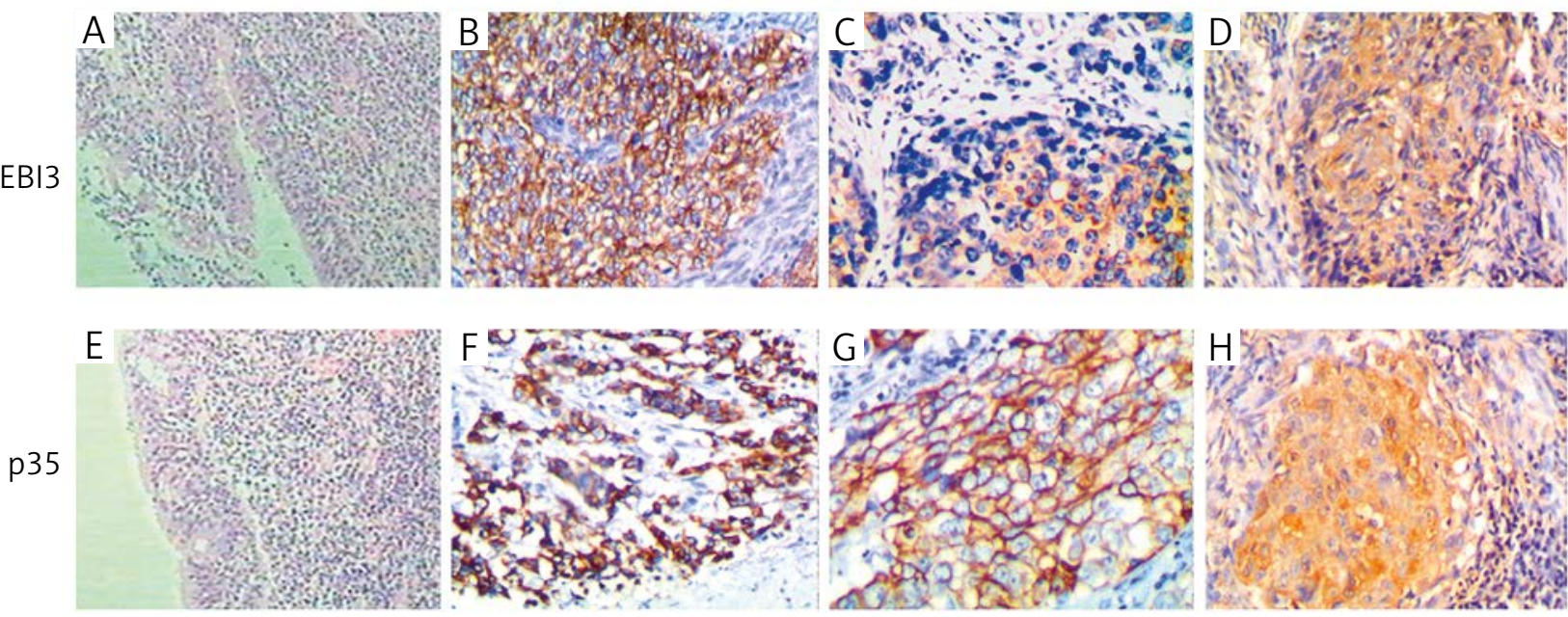

Fig. 1. EBI3 and p35 expression in nasopharyngeal carcinoma samples by immunohistochemistry. A, E) No staining of EBI3 and p35 in non-tumoural nasopharyngeal mucosa $(\times 200)$. B, C, D) Positive expression of EBI3 in the cytoplasmic of nasopharyngeal carcinoma cells (×200). F, G, H) Positive expression of p35 in the cytoplasmic of nasopharyngeal carcinoma cells $(\times 200)$
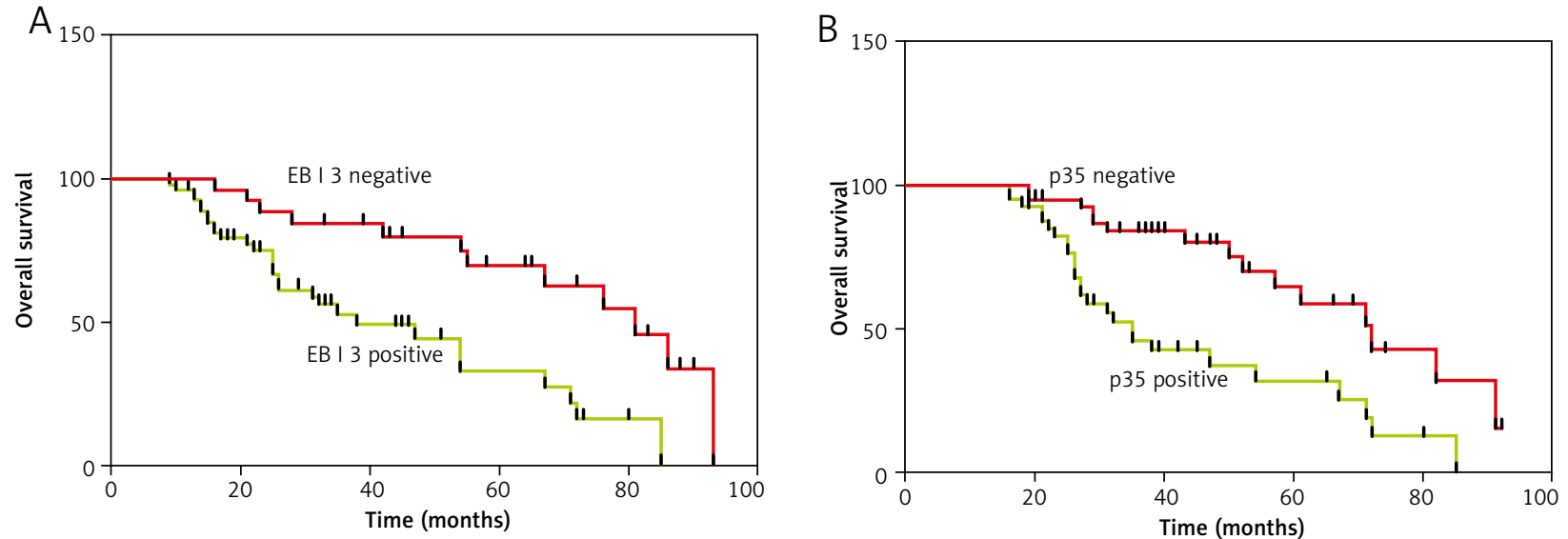

Fig. 2. Kaplan-Meier survival analysis according to EBI3 or p35 expression in nasopharyngeal carcinoma patients. A) The nasopharyngeal carcinoma patients with positive EBI3 expression had unfavourable prognosis compared to those with negative ones. B) The nasopharyngeal carcinoma patients with positive p35 expression had shorter survival times than those with negative expression

nificant correlations between EBI3 staining and sex, age, histological subtype, or T classification ( $p>0.05$ ). Similarly, there was a positive correlation between p35 expression and tumour stage $(p=0.002)$. These results demonstrated IL-35 participated in advancement of nasopharyngeal carcinoma.

The influence of EBI3 and p35 expressions on overall survival in patients with nasopharyngeal carcinoma

To assess the prognostic role of IL-35 in nasopharyngeal carcinoma patients, overall survival rates were estimated by Kaplan-Meier survival curves. As shown in Figure 2, patients with positive expression of EBI3 had a significantly shorter survival time than those cases with no staining of EBI3. Multivariate analyses of factors related to patient prognosis are shown in Table 2. Our results indicated that EBI3 was independently associated with patient outcome (hazard ratio $3.265,95 \% \mathrm{Cl} 1.175-7.335, p=0.042$ ). Addi- tionally, tumour stage (hazard ratio $3.137,95 \%$ Cl 1.306$8.423, p=0.031$ ) and lymph node metastasis (hazard ratio $0.145,95 \% \mathrm{Cl} 0.049-0.798, p=0.025$ ) were significantly correlated with patient survival. The prognostic impact of p35 was also analysed. Interestingly, although patients with 135 positive expression were associated with a worse overall survival $(p<0.05)$, multivariate analyses suggested p35 was not an independent prognostic predictor of nasopharyngeal carcinoma patients (hazard ratio 2.836; $95 \% \mathrm{Cl}$ $0.893-5.376, p=0.078)$. In all clinicopathological parameters, lymph node metastasis was the most independent factor for prognosis.

\section{Discussion}

Interleukin 35, a novel member of the IL family, had an immunosuppressive function of regulatory $T$ cells. As an anti-inflammatory cytokine, previous studies reported that IL-35 plays a vital role in the regulation of autoimmune diseases [17-19]. Recently, the effects of IL-35 involved in 
Table 2. Multivariate analysis of overall survival in nasopharyngeal carcinoma patients

$\begin{array}{lccc}\text { Factor } & \text { Hazard ratio } & \text { 95\% confidence interval } & p \text { value } \\ \text { Gender } & 1.482 & 0.613-3.435 & 0.236 \\ \text { Age [year] } & 1.142 & 0.922-1.059 & 0.547 \\ \text { Histological subtype } & 1.054 & 0.441-3.286 & 0.973 \\ \text { Tumour stage } & 3.137 & 1.306-8.423 & 0.031 \\ \text { T classification } & 0.772 & 0.296-2.784 & 0.794 \\ \text { Lymph node metastasis } & 0.145 & 0.049-0.798 & 0.025 \\ \text { EBI3 expression } & 3.265 & 1.175-7.335 & 0.042 \\ \text { p35 expression } & 2.836 & 0.893-5.376 & 0.078\end{array}$

the development and progression of cancer has attracted more attention. Taking into account immunosuppression of IL-35, it is not hard to see that it can contribute to the advancement of cancer. However, Long et al. [11] revealed that overexpression of IL-35 increased cell apoptosis and suppressed cell growth in human cancer cells. These contradictory findings demonstrate that the exact role of IL-35 on cancer, especially in nasopharyngeal carcinoma, needs further investigation.

To the best of our knowledge, this is the first study to investigate the role of IL-35 in the outcome of the nasopharyngeal carcinoma patients. In the present study, we have observed EBI3 and p35 staining localised in the cytoplasm of nasopharyngeal carcinoma cells. Moreover, as described in other cancers, both EBI3 and p35 were highly expressed in cancer cells compared with non-tumoural nasopharyngeal epithelium, indicating that they might be involved in the pathogenesis of nasopharyngeal carcinoma. Immunohistochemistry assay demonstrated that EBI3 and p35 staining were all significantly associated with advancement of tumour stage. Our results were consistent with the report from Zeng et al. [16], which stated that in colorectal cancer, higher levels of p35 and EBI3 expressions were noted in stage IV tumour samples. Furthermore, EBI3 expression was also correlated with lymph node metastasis. These findings suggest that IL-35 is vital for progression of nasopharyngeal carcinoma. To better elucidate the clinical significance of IL-35 in nasopharyngeal carcinoma, we are further studying the impact of IL-35 on the prognosis of patients with nasopharyngeal carcinoma.

A significant reduction in serum IL-35 was noted in patients after surgical resection, and IL-35 promoted progression of colorectal cancer and influenced prognosis of colorectal cancer patients. Ito et al. reported that a high level of EBI3 expression was associated with a poor prognosis of lung cancer, and that it is an independent prognostic factor. In this study we also observed that negative expression of $\mathrm{EB} 13$ was significantly associated with a better prognosis and prolonged overall survival. Interestingly, although p35 positive expression was associated with a worse survival, multivariate analyses suggested p35 was not an independent prognostic predictor.

In summary, in the present study, we evaluated the expression pattern of IL-35 in nasopharyngeal carcinoma cells and its association with clinicopathological factors.
Our data suggest that IL-35 is involved in the progression of nasopharyngeal carcinoma. Moreover, expressions of $\mathrm{EBI} 3$ and $\mathrm{p} 35$ are correlated with unfavourable prognosis. Therefore, IL-35 may be a new biomarker for the prognosis of nasopharyngeal carcinoma patients.

The authors declare no conflict of interest.

\section{References}

1. Jemal A, Bray F, Center MM, Ferlay J, Ward E, Forman D. Global cancer statistics. CA Cancer J Clin 2011; 61: 69-90.

2. Tulalamba W, Janvilisri T. Nasopharyngeal carcinoma signaling pathway: an update on molecular biomarkers. Int J Cell Biol 2012; 2012: 594681.

3. Devergne O, Birkenbach M, Kieff E. Epstein-Barr virus-induced gene 3 and the 355 subunit of interleukin 12 form a novel heterodimeric hematopoietin. Proc Natl Acad Sci U S A 1997; 94: 12041-6.

4. Niedbala W, Wei XQ, Cai B, Hueber AJ, Leung BP, Mclnnes IB, Liew FY. IL-35 is a novel cytokine with therapeutic effects against collagen-induced arthritis through the expansion of regulatory $T$ cells and suppression of Th17 cells. Eur J Immunol 2007; 37: 3021-39.

5. Collison LW, Workman CJ, Kuo TT, et al. The inhibitory cytokine IL-35 contributes to regulatory T-cell function. Nature 2007; 450: 566-9.

6. Pflanz S, Timans JC, Cheung J, et al. IL-27, a heterodimeric cytokine composed of EBI3 and p28 protein, induces proliferation of naive CD4 (+) T cells. Immunity 2002; 16: 779-90.

7. Chaturvedi V, Collison LW, Guy CS, Workman CJ, Vignali DA. Cutting edge: human regulatory $T$ cells require IL-35 to mediate suppression and infectious tolerance. J Immunol 2011; 186: 6661-6.

8. Seyerl M, Kirchberger S, Majdic O, Seipelt J, Jindra C, Schrauf C, Stöckl J. Human rhinoviruses induce IL-35-producing Treg via induction of B7-H1 (CD274) and sialoadhesin (CD169) on DC. Eur I Immunol 2010; 40: 321-9.

9. Collison LW, Pillai MR, Chaturvedi V, Vignali DA. Regulatory T cell suppression is potentiated by target $T$ cells in a cell contact, IL-35and IL-10-dependent manner. I Immunol 2009; 182: 6121-8.

10. Collison LW, Chaturvedi V, Henderson AL, et al. IL-35-mediated induction of a potent regulatory $T$ cell population. Nat Immunol 2010; 11: 1093-101.

11. Long J, Zhang X, Wen M, Kong Q, Lv Z, An Y, Wei XQ. IL-35 over-expression increases apoptosis sensitivity and suppresses cell growth in human cancer cells. Biochem Biophys Res Commun 2013; 430: 364-9.

12. Wang Z, Liu JQ, Liu Z, et al. Tumor-derived IL-35 promotes tumor growth by enhancing myeloid cell accumulation and angiogenesis. J Immunol 2013; 190: 2415-23.

13. Larousserie F, Bardel E, Pflanz S, Arnulf B, Lome-Maldonado C, Hermine O. Analysis of interleukin-27 (EBI3/p28) expression in Epstein-Barr virus- and human T-cell leukemia virus type 1-asso- 
ciated lymphomas: heterogeneous expression of EBI3 subunit by tumoral cells. Am J Pathol 2005; 166: 1217-28.

14. Niedobitek G, Pazolt D, Teichmann M, Devergne O. Frequent ex pression of the Epstein-Barr virus (EBV)-induced gene, EBI3, an IL-12 p40-related cytokine, in Hodgkin and Reed-Sternberg cells. J Pathol 2002; 198: 310-6.

15. Nishino R, Takano A, Oshita H, et al. Identification of Epstein-Barr virus-induced gene 3 as a novel serum and tissue biomarker and a therapeutic target for lung cancer. Clin Cancer Res 2011; 17: 6272-86.

16. Zeng JC, Zhang Z, Li TY, et al. Assessing the role of IL-35 in colorectal cancer progression and prognosis. Int I Clin Exp Pathol 2013; 6: 1806-16.

17. Li X, Mai J, Virtue A, et al. IL-35 is a novel responsive anti-inflammatory cytokine - a new system of categorizing anti-inflammatory cytokines. PLoS One 2012; 7: e33628.

18. Whitehead GS, Wilson RH, Nakano K, Burch LH, Nakano H, Cook DN. IL-35 production by inducible costimulator (ICOS)-positive regulatory T cells reverses established IL-17-dependent allergic airways disease. J Allergy Clin Immunol 2012; 129: 207-15.

19. Kochetkova I, Golden S, Holderness K, Callis G, Pascual DW. IL-35 stimulation of $\mathrm{CD} 39+$ regulatory $T$ cells confers protection against collagen II-induced arthritis via the production of IL-10. Immunol 2010; 184: 7144-53.

\section{Address for correspondence}

\section{Sun Hong}

Xiangya Hospital

Central South University

410008 Changsha

China

e-mail: sunhong981@126.com

Submitted: 9.03 .2014

Accepted: 9.06.2014 